\title{
Most of Africa's Nutritionally Deprived Women and Children are Not Found in Poor Households
}

DOI:

10.1162/rest_a_00800

\section{Document Version}

Accepted author manuscript

Link to publication record in Manchester Research Explorer

\section{Citation for published version (APA):}

Brown, C., Ravallion, M., \& van de Walle, D. (2019). Most of Africa's Nutritionally Deprived Women and Children are Not Found in Poor Households. Review of Economics and Statistics, 101(4), 631-644.

https://doi.org/10.1162/rest_a_00800

\section{Published in:}

Review of Economics and Statistics

\section{Citing this paper}

Please note that where the full-text provided on Manchester Research Explorer is the Author Accepted Manuscript or Proof version this may differ from the final Published version. If citing, it is advised that you check and use the publisher's definitive version.

\section{General rights}

Copyright and moral rights for the publications made accessible in the Research Explorer are retained by the authors and/or other copyright owners and it is a condition of accessing publications that users recognise and abide by the legal requirements associated with these rights.

\section{Takedown policy}

If you believe that this document breaches copyright please refer to the University of Manchester's Takedown Procedures [http://man.ac.uk/04Y6Bo] or contact uml.scholarlycommunications@manchester.ac.uk providing relevant details, so we can investigate your claim.

\section{OPEN ACCESS}




\title{
MOST OF AFRICA'S NUTRITIONALLY DEPRIVED WOMEN AND CHILDREN ARE NOT FOUND IN POOR HOUSEHOLDS
}

\author{
Caitlin Brown, Martin Ravallion, and Dominique van de Walle*
}

Abstract-Policymakers often assume that targeting observably poor households suffices in reaching nutritionally deprived individuals. We question that assumption. Our comprehensive assessment for sub-Saharan Africa reveals that undernourished women and children are spread widely across the household wealth and consumption distributions. Roughly three-quarters of underweight women and undernourished children are not found in the poorest $20 \%$ of households, and around half are not found in the poorest $40 \%$. Countries with higher undernutrition tend to have higher shares of undernourished individuals in nonpoor households. Intrahousehold inequality accounts in part for our results, but other factors appear to be important, including common health risks.

\section{Introduction}

W HILE it is widely appreciated that poverty is an individual deprivation, household aggregate data are almost invariably used to infer individual deprivations, including undernutrition. An array of social programs are targeted on this basis, typically using readily available proxies for household consumption or income per person. ${ }^{1}$ Partly in response to concerns about chronic undernutrition in certain regions, including in Africa, there is an expanding effort at social protection in developing countries, and this effort is typically focused on transfers targeted to poor families. ${ }^{2}$ For its part, the World Bank has made reaching poor families - as often identified by the poorest two quintiles of people based on household consumption per person-the main objective of its social protection operations.

Three main reasons can be identified as to why the idea of reaching deprived individuals using antipoverty programs that explicitly target poor households is attractive to policymakers. First, there is a data constraint: standard data sources do not allow us to measure individual consumption. Second, interventions at the individual level may be seen to be paternalistic and intrusive (as they require intervention within families) and may well be costly (to the extent that they rely

Received for publication January 5, 2018. Revision accepted for publication June 18, 2018. Editor: Amitabh Chandra.

*Brown: Central European University; Ravallion: Georgetown University; van de Walle: World Bank.

We are grateful to the World Bank's Strategic Research Program for funding assistance. Helpful comments were received from Harold Alderman, Arthur Alik-Lagrange, Denis Cogneau, Emanuela Galasso, Sylvie Lambert, Kate Rybczynski, and Adam Wagstaff; seminar participants at Georgetown University, University of California Riverside, Paris School of Economics, and University of Guelph; and the journal's editor and referees. These are our own the views and need not reflect those of our employers.

A supplemental appendix is available online at http://www.mitpress journals.org/doi/suppl/10.1162/rest_a_00800.

${ }^{1}$ On these programs in developing countries, see Coady, Grosh, and Hoddinott, (2004), Fiszbein and Schady (2010), Ruel, Alderman, and Maternal and Child Nutritian Study Group (2013), Del Ninno and Mills (2015), and Ravallion (2016).

${ }^{2}$ For evidence on the expansion in social protection programs in developing countries, see Ravallion (2016). Various case studies of these programs in Africa are found in Del Ninno and Mills (2015). on fine targeting, constrained by the fact that individual deprivations are not comprehensively observed in large populations). Third, in supporting this idea, an appeal can be made to a large literature that has documented that poorer households in terms of consumption, income, or wealth are more likely to include deprived individuals. ${ }^{3}$ Aggregate household resources constrain consumption for all household members. For these reasons, it is not surprising that in practice, many social policies hope to reach deprived individuals by targeting seemingly poor households.

The existence of a household wealth effect on individual welfare, however, does not imply that targeting poor households will be very effective in reaching nutritionally deprived individuals. One can point to empirical evidence casting doubt on that assumption, including the evidence that rejects a unitary model of the household, suggesting there are sources of inequality within households that have been assumed away in much past thinking about antipoverty policies. ${ }^{4}$ There is also evidence of discrimination against certain household members such as orphans and widows and the evidence of unequal exposure to transitory shocks. The health environment is another source of heterogeneity in individual nutrition at given household wealth. While the well-off are better able to protect their children's nutrition and health status from weak public provisioning and poor health environments, the powerful role of complementarities and externalities in water, sanitation, and hygiene means that the better-off also remain vulnerable to these deficiencies. ${ }^{5}$ Heterogeneity in factors influencing individual deprivation can also mean that transfers to poor households miss deprived individuals. Policy effectiveness depends on the ability to reach households that include deprived individuals and the ability to reach deprived individuals within those households, which will depend on how resources are allocated internally.

This paper focuses on the first issue, and specifically nutritional deprivations at the individual level, as indicated by anthropometric measures. Undernutrition can stem from inadequate caloric intakes or deficiencies in protein or micronutrient intakes, or from illness that impedes nutritional absorption. Anthropometric indicators reflect both intakes and absorption. Nutritional deprivations are of direct and immediate concern, and there is also evidence of longer-term social and economic costs, especially of low birthweight and chronic undernutrition in childhood. While nutritional status

\footnotetext{
${ }^{3}$ Reviewed in Ravallion (2016). The literature is reviewed in the online supplement.

${ }^{4}$ We elaborate on these points later and provide references to the literature in the supplement.

${ }^{5}$ The supplement provides a literature review and a formal expository model of how these sources of heterogeneity influence measures of undernutrition.
} 
is sometimes used as a proxy for individual poverty (as in, for example, Steckel, 1995), it is clearly only one dimension of poverty. Nonetheless, donors, policymakers, and civil society groups are specifically interested in addressing deprivations associated with undernutrition. There are various forms of direct interventions with the aim of improving nutrition, including direct nutrition supplementation and better health practices. ${ }^{6}$ While these policies are sometimes implemented through health clinics or schools, there is a growing interest in doing so through household-based policies—by integrating nutrition programs within antipoverty policies more broadly. We assess how well this might work given the data available.

The paper uses data for thirty countries in sub-Saharan Africa (SSA), where chronic undernutrition among children is a major policy concern. The latest data at the time of writing indicate that the incidence of child stunting in SSA has been falling, but not fast enough to prevent rising numbers; in 2017, UNICEF estimates that 58 million children are stunted in SSA. ${ }^{7}$ We draw on anthropometric data for 390,000 women and children from the Demographic and Health Surveys (DHS) to identify nutritionally vulnerable women and children. These surveys also include a household wealth index based on a household's assets and living conditions. We use this index as a proxy for household wealth. To help address concerns about measurement errors in the DHS wealth index, we reweight and augment the index so as to best predict undernutrition. However, aggregate consumption may well be a better indicator of household welfare than the DHS wealth index, which (for example) may not respond quickly to shocks. We therefore also test robustness to using instead good-quality nationally representative household consumption surveys from the World Bank's Living Standards Measurement Study (LSMS).

The main contribution of the paper is to show systematically that although the incidence of undernutrition tends to be higher in poorer households, nutritional deprivations are spread quite widely through both the wealth and consumption distributions, such that the joint probability of being an underweight woman or child and living in the poorest household wealth quintile is low. We find that about $75 \%$ of underweight women and undernourished children are not found in the poorest $20 \%$ of households, and half are not found in the poorest $40 \%$. This pattern is less pronounced but still holds when we use a regression to control for various individualand household-level factors that may influence nutritional outcomes.

Our results point to the need for broad coverage and attention to individuals in efforts to address undernutrition rather than subsuming this problem within antipoverty interventions that are targeted at the household-level. Data availability limits how far we can go in explaining our findings, but we point to evidence suggesting that common health risks play

\footnotetext{
${ }^{6}$ See, for example, the package of nutritional interventions described in Bhutta et al. (2013).

${ }^{7}$ See UNICEF's website.
}

an important role. Intrahousehold inequality in nutritional outcomes, such that the undernourished are found across a range of households, is also a contributing factor. However, many of our key findings continue to hold even after accounting for inequalities within the household.

Section II reviews the data we use. Section III presents the main findings, while section IV discusses various explanations for our results. Section V concludes.

\section{Data}

Our data are drawn from the most recent DHS available at the time of writing and recent LSMS surveys that collected nutrition data. ${ }^{8}$ The supplement gives details on the sample sizes and years for all the surveys.

\section{A. Individual Nutritional Outcomes}

We study the nutritional outcomes of women and children. For women, we employ body mass index (BMI) and an indicator for being underweight, set equal to 1 if a woman's BMI is lower than 18.5 and 0 otherwise. ${ }^{9}$ The DHS compute BMI for samples of women aged 15 through 49 and exclude values smaller than 12 and greater than 60 , as these are almost certainly measurement errors. We do the same for the consumption surveys. We also exclude all women who report being pregnant at the survey date. ${ }^{10}$

Anthropometric data are available for all children aged under 5. We use the $z$-scores for height-for-age and weightfor-height to create measures of stunting and wasting, respectively. ${ }^{11}$ A child is deemed to be stunted if his height-forage $z$-score is 2 standard deviations below the median of the reference group; wasting is defined similarly using weightfor-height. Stunting and wasting have different causes and effects. Stunting is an indicator of persistent, longer-term, chronic undernutrition from which it is much harder for a child to recover, and it is known that stunting has adverse longer-term consequences for child development. ${ }^{12}$ Wasting tends to be more responsive to short-term (possibly seasonal) food deprivations or illnesses.

Table 1 gives the summary statistics for the nutritional outcomes for women and children using the DHS and

\footnotetext{
${ }^{8}$ DHS for the Central African Republic, Chad, Comoros, Madagascar, São Tomé, and Principe, and South Africa are excluded due to older survey formats that did not contain key variables.

${ }^{9} \mathrm{BMI}$ is also known as the Quetelet index. It is defined as a woman's weight (in kilograms) divided by her height (in meters squared).

${ }^{10}$ We are unable to exclude pregnant women for Tanzania's LSMS because the information is missing. On average, pregnant women represent $10 \%$ of women aged 15 to 49 . See the supplement. We also dropped observations with missing values for variables used in the paper to ensure consistent and comparable sample sizes throughout. We tested the effect of relaxing this constraint and found that it makes negligible difference to the results.

${ }^{11}$ These variables are already constructed in the DHS. For LSMS surveys, we use the Stata command zscore06 to convert height and weight into standardized values. Z-scores are calculated using the WHO 2006 standard.

${ }^{12}$ See, for example, Walker et al. (2007) and Hoddinott et al. (2008).
} 
TABLE 1.-Summary Statistics FOR Nutritional IndiCATORS Using DHS AND LSMS

\begin{tabular}{|c|c|c|c|c|c|c|c|}
\hline & \multirow{2}{*}{$\begin{array}{c}\text { Underweight } \\
\text { Women }\end{array}$} & \multicolumn{3}{|c|}{ Stunted Children } & \multicolumn{3}{|c|}{ Wasted Children } \\
\hline & & Boys & Girls & Mean & Boys & Girls & Mean \\
\hline Benin & 0.062 & 0.434 & 0.378 & 0.407 & 0.154 & 0.136 & 0.145 \\
\hline Burkina Faso & 0.155 & 0.317 & 0.283 & 0.300 & 0.152 & 0.128 & 0.140 \\
\hline Burundi & 0.159 & 0.55 & 0.473 & 0.512 & 0.052 & 0.048 & 0.050 \\
\hline Cameroon & 0.068 & 0.289 & 0.264 & 0.276 & 0.056 & 0.041 & 0.049 \\
\hline Congo & 0.143 & 0.175 & 0.199 & 0.187 & 0.046 & 0.054 & 0.050 \\
\hline Côte d'Ivoire & 0.077 & 0.254 & 0.222 & 0.237 & 0.079 & 0.064 & 0.071 \\
\hline Democratic Republic of the Congo & 0.142 & 0.379 & 0.355 & 0.367 & 0.084 & 0.059 & 0.071 \\
\hline Ethiopia & 0.267 & 0.395 & 0.381 & 0.388 & 0.096 & 0.078 & 0.087 \\
\hline Gabon & 0.072 & 0.146 & 0.12 & 0.133 & 0.035 & 0.028 & 0.031 \\
\hline Gambia & 0.166 & 0.208 & 0.192 & 0.200 & 0.127 & 0.094 & 0.111 \\
\hline Ghana & 0.061 & 0.137 & 0.13 & 0.134 & 0.049 & 0.056 & 0.053 \\
\hline Guinea & 0.122 & 0.278 & 0.255 & 0.267 & 0.103 & 0.096 & 0.099 \\
\hline Kenya & 0.124 & 0.305 & 0.29 & 0.298 & 0.064 & 0.050 & 0.057 \\
\hline Lesotho & 0.060 & 0.328 & 0.292 & 0.310 & 0.037 & 0.025 & 0.031 \\
\hline Liberia & 0.074 & 0.272 & 0.235 & 0.255 & 0.059 & 0.060 & 0.059 \\
\hline Malawi & 0.086 & 0.445 & 0.387 & 0.416 & 0.043 & 0.035 & 0.039 \\
\hline Mali & 0.115 & 0.335 & 0.335 & 0.335 & 0.117 & 0.119 & 0.118 \\
\hline Mozambique & 0.085 & 0.381 & 0.359 & 0.370 & 0.053 & 0.047 & 0.050 \\
\hline Namibia & 0.138 & 0.181 & 0.174 & 0.177 & 0.104 & 0.057 & 0.080 \\
\hline Niger & 0.151 & 0.368 & 0.354 & 0.361 & 0.165 & 0.147 & 0.156 \\
\hline Nigeria & 0.114 & 0.346 & 0.319 & 0.333 & 0.174 & 0.162 & 0.168 \\
\hline Rwanda & 0.072 & 0.395 & 0.353 & 0.374 & 0.032 & 0.021 & 0.026 \\
\hline Senegal & 0.223 & 0.163 & 0.152 & 0.157 & 0.111 & 0.066 & 0.089 \\
\hline Sierra Leone & 0.091 & 0.332 & 0.328 & 0.330 & 0.083 & 0.082 & 0.082 \\
\hline Swaziland & 0.032 & 0.246 & 0.203 & 0.225 & 0.028 & 0.018 & 0.023 \\
\hline Tanzania & 0.113 & 0.372 & 0.338 & 0.355 & 0.043 & 0.038 & 0.040 \\
\hline Togo & 0.069 & 0.221 & 0.213 & 0.217 & 0.073 & 0.054 & 0.064 \\
\hline Uganda & 0.118 & 0.309 & 0.256 & 0.283 & 0.039 & 0.039 & 0.039 \\
\hline Zambia & 0.102 & 0.357 & 0.328 & 0.343 & 0.054 & 0.054 & 0.054 \\
\hline Zimbabwe & 0.071 & 0.271 & 0.238 & 0.254 & 0.032 & 0.024 & 0.028 \\
\hline Mean & 0.113 & 0.336 & 0.309 & 0.323 & 0.094 & 0.082 & 0.088 \\
\hline \multicolumn{8}{|l|}{ Using LSMS } \\
\hline Burkina Faso & NA & 0.382 & 0.301 & 0.343 & 0.126 & 0.092 & 0.110 \\
\hline Ethiopia & NA & 0.409 & 0.403 & 0.406 & 0.132 & 0.107 & 0.119 \\
\hline Ghana & 0.084 & 0.326 & 0.330 & 0.328 & 0.200 & 0.192 & 0.196 \\
\hline Malawi & NA & 0.282 & 0.238 & 0.260 & 0.080 & 0.079 & 0.079 \\
\hline Nigeria & NA & 0.242 & 0.227 & 0.235 & 0.119 & 0.090 & 0.105 \\
\hline Tanzania & 0.132 & 0.138 & 0.102 & 0.120 & 0.043 & 0.053 & 0.048 \\
\hline Uganda & NA & 0.346 & 0.241 & 0.291 & 0.042 & 0.036 & 0.039 \\
\hline Mean & NA & 0.306 & 0.269 & 0.287 & 0.102 & 0.087 & 0.094 \\
\hline
\end{tabular}

The table gives the average values for nutritional outcomes for women and children by country. Means are population weighted. Observations with missing values have been dropped. NA: the required variable is not available in the survey.

LSMS. ${ }^{13}$ Focusing on the larger sample of countries available in the DHS and taking population-weighted averages, we find that $11 \%$ of adult women are underweight, while $32 \%$ of children are stunted and 9\% are wasted (similar numbers are found for children in the LSMS). Boys are found to have a generally higher incidence of both stunting and wasting relative to girls, although not all the differences at the country level are statistically significant. ${ }^{14}$ Across countries, a higher incidence of underweight women is associated with a higher incidence of wasted children $(r=0.39$, significant at the $5 \%$ level). The correlation between women's and children's nutritional status is weaker for stunting $(r=0.13) .{ }^{15}$ This is

\footnotetext{
${ }^{13}$ There are some discrepancies in the means between the two data sets, much of which is likely to do with the timing of the surveys, although differences in sample selection and measurement may also be contributing.

${ }^{14}$ This result for the African context was first discussed in Svedberg (1990). Since then, others report similar findings for Africa (e.g., World Health Organization, 2016, and Wamani et al., 2007).

${ }^{15}$ This weak correlation between wasting and stunting is not surprising (Victora, 1992). Although there is some evidence that wasting in early
}

what we would expect if a woman being underweight and her children being wasted are caused by similar short-term shocks, while stunting is a more long-term condition.

For a subset of countries, the DHS collected data on adult male anthropometrics, which provide insight into the extent of intrahousehold inequality. Table 2 provides summary statistics on the incidence of undernutrition for women and children stratified according to whether the male head of household is underweight. We see that the incidence of undernutrition among women and children is lower when the male head is adequately nourished. However, substantial inequality in nutritional status is also evident, and the gender inequality goes in both directions. The majority of women in households where the male head is underweight are not undernourished, and there is a high incidence of undernutrition among women and children in households where the

childhood can cause subsequent stunting (Richard et al., 2012), the fact that stunting is a longer-term condition while wasting tends to be more transient points to different causative factors. 
TAble 2.- Incidence of Underweight For Countries with Data on MaLe BMi

\begin{tabular}{|c|c|c|c|c|c|c|c|c|c|c|c|c|}
\hline & \multirow{2}{*}{\multicolumn{2}{|c|}{ Underweight }} & \multicolumn{5}{|c|}{ Male Head Is Underweight } & \multicolumn{5}{|c|}{ Male Head Is Not Underweight } \\
\hline & & & \multirow[b]{2}{*}{ Underweight women } & \multicolumn{2}{|c|}{ Stunted } & \multicolumn{2}{|c|}{ Wasted } & \multirow[b]{2}{*}{ Underweight women } & \multicolumn{2}{|c|}{ Stunted } & \multicolumn{2}{|c|}{ Wasted } \\
\hline & Men & Women & & Boys & Girls & Boys & Girls & & Boys & Girls & Boys & Girls \\
\hline Ethiopia & 0.37 & 0.27 & $\begin{array}{c}0.33 \\
(0.33)\end{array}$ & $\begin{array}{c}0.40 \\
(0.31)\end{array}$ & $\begin{array}{c}0.38 \\
(0.27)\end{array}$ & $\begin{array}{c}0.14 \\
(0.45)\end{array}$ & $\begin{array}{c}0.10 \\
(0.35)\end{array}$ & $\begin{array}{c}0.26 \\
(0.67)\end{array}$ & $\begin{array}{c}0.37 \\
(0.69)\end{array}$ & $\begin{array}{c}0.35 \\
(0.73)\end{array}$ & $\begin{array}{c}0.07 \\
(0.55)\end{array}$ & $\begin{array}{c}0.06 \\
(0.65)\end{array}$ \\
\hline Ghana & 0.10 & 0.06 & $\begin{array}{c}0.17 \\
(0.14)\end{array}$ & $\begin{array}{c}0.27 \\
(0.13)\end{array}$ & $\begin{array}{c}0.19 \\
(0.07)\end{array}$ & $\begin{array}{c}0.09 \\
(0.12)\end{array}$ & $\begin{array}{c}0.11 \\
(0.08)\end{array}$ & $\begin{array}{c}0.06 \\
(0.86)\end{array}$ & $\begin{array}{c}0.12 \\
(0.87)\end{array}$ & $\begin{array}{c}0.13 \\
(0.93)\end{array}$ & $\begin{array}{c}0.04 \\
(0.88)\end{array}$ & $\begin{array}{c}0.06 \\
(0.92)\end{array}$ \\
\hline Lesotho & 0.19 & 0.06 & $\begin{array}{c}0.07 \\
(0.14)\end{array}$ & $\begin{array}{c}0.54 \\
(0.21)\end{array}$ & $\begin{array}{c}0.22 \\
(0.11)\end{array}$ & $\begin{array}{c}0.07 \\
(0.20)\end{array}$ & $\begin{array}{c}0.02 \\
(0.08)\end{array}$ & $\begin{array}{c}0.04 \\
(0.86)\end{array}$ & $\begin{array}{c}0.26 \\
(0.79)\end{array}$ & $\begin{array}{c}0.25 \\
(0.89)\end{array}$ & $\begin{array}{c}0.03 \\
(0.80)\end{array}$ & $\begin{array}{c}0.03 \\
(0.92)\end{array}$ \\
\hline Namibia & 0.23 & 0.14 & $\begin{array}{c}0.27 \\
(0.27)\end{array}$ & $\begin{array}{c}0.21 \\
(0.19)\end{array}$ & $\begin{array}{c}0.22 \\
(0.17)\end{array}$ & $\begin{array}{c}0.12 \\
(0.21)\end{array}$ & $\begin{array}{c}0.00 \\
(0.00)\end{array}$ & $\begin{array}{c}0.10 \\
(0.73)\end{array}$ & $\begin{array}{c}0.17 \\
(0.81)\end{array}$ & $\begin{array}{c}0.17 \\
(0.83)\end{array}$ & $\begin{array}{c}0.09 \\
(0.79)\end{array}$ & $\begin{array}{c}0.05 \\
(1.00)\end{array}$ \\
\hline Rwanda & 0.16 & 0.07 & $\begin{array}{c}0.13 \\
(0.21)\end{array}$ & $\begin{array}{c}0.42 \\
(0.11)\end{array}$ & $\begin{array}{c}0.33 \\
(0.10)\end{array}$ & $\begin{array}{c}0.07 \\
(0.26)\end{array}$ & $\begin{array}{c}0.04 \\
(0.24)\end{array}$ & $\begin{array}{c}0.06 \\
(0.79)\end{array}$ & $\begin{array}{c}0.38 \\
(0.89)\end{array}$ & $\begin{array}{c}0.35 \\
(0.90)\end{array}$ & $\begin{array}{c}0.02 \\
(0.74)\end{array}$ & $\begin{array}{c}0.01 \\
(0.76)\end{array}$ \\
\hline Senegal & 0.28 & 0.22 & $\begin{array}{c}0.31 \\
(0.20)\end{array}$ & $\begin{array}{c}0.27 \\
(0.18)\end{array}$ & $\begin{array}{c}0.19 \\
(0.15)\end{array}$ & $\begin{array}{c}0.10 \\
(0.18)\end{array}$ & $\begin{array}{c}0.08 \\
(0.15)\end{array}$ & $\begin{array}{c}0.21 \\
(0.81)\end{array}$ & $\begin{array}{c}0.18 \\
(0.82)\end{array}$ & $\begin{array}{c}0.18 \\
(0.85)\end{array}$ & $\begin{array}{c}0.07 \\
(0.82)\end{array}$ & $\begin{array}{c}0.08 \\
(0.85)\end{array}$ \\
\hline Sierra Leone & 0.16 & 0.09 & $\begin{array}{c}0.14 \\
(0.13)\end{array}$ & $\begin{array}{c}0.27 \\
(0.07)\end{array}$ & $\begin{array}{c}0.29 \\
(0.08)\end{array}$ & $\begin{array}{c}0.10 \\
(0.12)\end{array}$ & $\begin{array}{c}0.06 \\
(0.08)\end{array}$ & $\begin{array}{c}0.09 \\
(0.87)\end{array}$ & $\begin{array}{c}0.28 \\
(0.93)\end{array}$ & $\begin{array}{c}0.28 \\
(0.92)\end{array}$ & $\begin{array}{c}0.06 \\
(0.88)\end{array}$ & $\begin{array}{c}0.06 \\
(0.92)\end{array}$ \\
\hline Mean & 0.24 & 0.16 & $\begin{array}{c}0.28 \\
(0.28)\end{array}$ & $\begin{array}{c}0.38 \\
(0.22)\end{array}$ & $\begin{array}{c}0.33 \\
(0.18)\end{array}$ & $\begin{array}{c}0.13 \\
(0.33)\end{array}$ & $\begin{array}{c}0.08 \\
(0.23)\end{array}$ & $\begin{array}{c}0.15 \\
(0.72)\end{array}$ & $\begin{array}{c}0.30 \\
(0.78)\end{array}$ & $\begin{array}{c}0.29 \\
(0.82)\end{array}$ & $\begin{array}{c}0.06 \\
(0.67)\end{array}$ & $\begin{array}{c}0.05 \\
(0.77)\end{array}$ \\
\hline
\end{tabular}

The table shows the proportion of underweight women and children in male-headed households separated by whether the male head is underweight. Numbers in parentheses are the shares of women or children who are undernourished found in each of the two household groups. Men and women are restricted to ages 15 to 49 years. Children are up to 5 years of age. Data are drawn from DHS. Means are population weighted.

male head is not underweight. Table 2 also gives (in parentheses) the proportions of undernourished women and children found in the two groups of households, identified by whether the male head is underweight. (The proportions sum to unity horizontally.) We see that on average, the bulk of underweight women $(72 \%)$ are found in households where the male head is not underweight, and the same is true for stunted $(80 \%)$ and wasted $(72 \%)$ children.

\section{B. Wealth and Other Covariates}

When we say that a household is "wealth poor" we are referring to the DHS wealth index within a given country. The wealth index is a composite of variables related to a household's assets and amenities, including materials used for housing construction and its access to water and sanitation. These variables are then aggregated by the DHS into an index using factor-analytic methods, with the wealth index being identified as the first principal component of the data. The DHS wealth index comes as a $z$-score-standardized with mean 0 and standard deviation of unity. So the index is country specific - not intended to be comparable across countries.

We focus on the poorest $20 \%$ and $40 \%$ of households based on the wealth index. These are arbitrary choices, although the $40 \%$ figure is close to the overall poverty rate found for SSA using the World Bank's international line. ${ }^{16}$ The $20 \%$ figure allows us to focus on the lower part of the wealth distribution. We also provide key results for the full distribution.

In practice, policymakers almost never have access to accurate measures of wealth or consumption. Nonetheless, it should not be forgotten that the DHS wealth index is a proxy, not a direct measure of wealth. The index focuses on durable

\footnotetext{
${ }^{16}$ Using the World Bank's international line of \$1.90 a day at 2011 purchasing power parity, $43 \%$ of the population of sub-Saharan Africa are found to be poor in 2013 (based on PovcalNet).
}

and productive asset wealth rather than labor or education wealth, arguably the main assets of many among the poor. We also conduct the analysis using household consumption per capita for the subset of countries for which this is feasible. Surveys that contain detailed household consumption data as well as anthropometrics for women and children are not common, but some do exist, including within recent LSMSs as listed in the supplement. ${ }^{17}$ The consumption variable is spatially deflated and expressed in per capita terms.

\section{Individual Outcomes and Household Wealth}

\section{A. Wealth Effects on Nutritional Status}

Figure 1 plots the incidence of the three anthropometric indices against percentiles of the household wealth index. Given that younger women typically have a lower BMI, we plot incidence for all women 15 to 49 years of age, as well as for women 20 to 49 years of age. The wealth effect, whereby nutritional status improves with a higher DHS wealth index, is generally evident. However, aside from child stunting, the wealth effect is clearly weak in most countries. The incidence of being underweight is slightly higher for younger women, although the relationship with household wealth is very similar. Child wasting in some countries shows little or no sign of the wealth effect (notably Gabon, Gambia, Senegal, Sierra Leone, and Swaziland). The supplement gives the corresponding graphs using household consumption per capita for the LSMS surveys that have anthropometric data. Similar comments apply.

The overall strength of the household wealth effect for each country can be assessed by regressing the standardized values for nutritional status (that is, the $z$-score for women's BMI

\footnotetext{
${ }^{17}$ Only the Ghana LSMS is not one of the Integrated Surveys on Agriculture within the LSMS.
} 
Figure 1.-Nutritional Outcomes AND Household WeALth
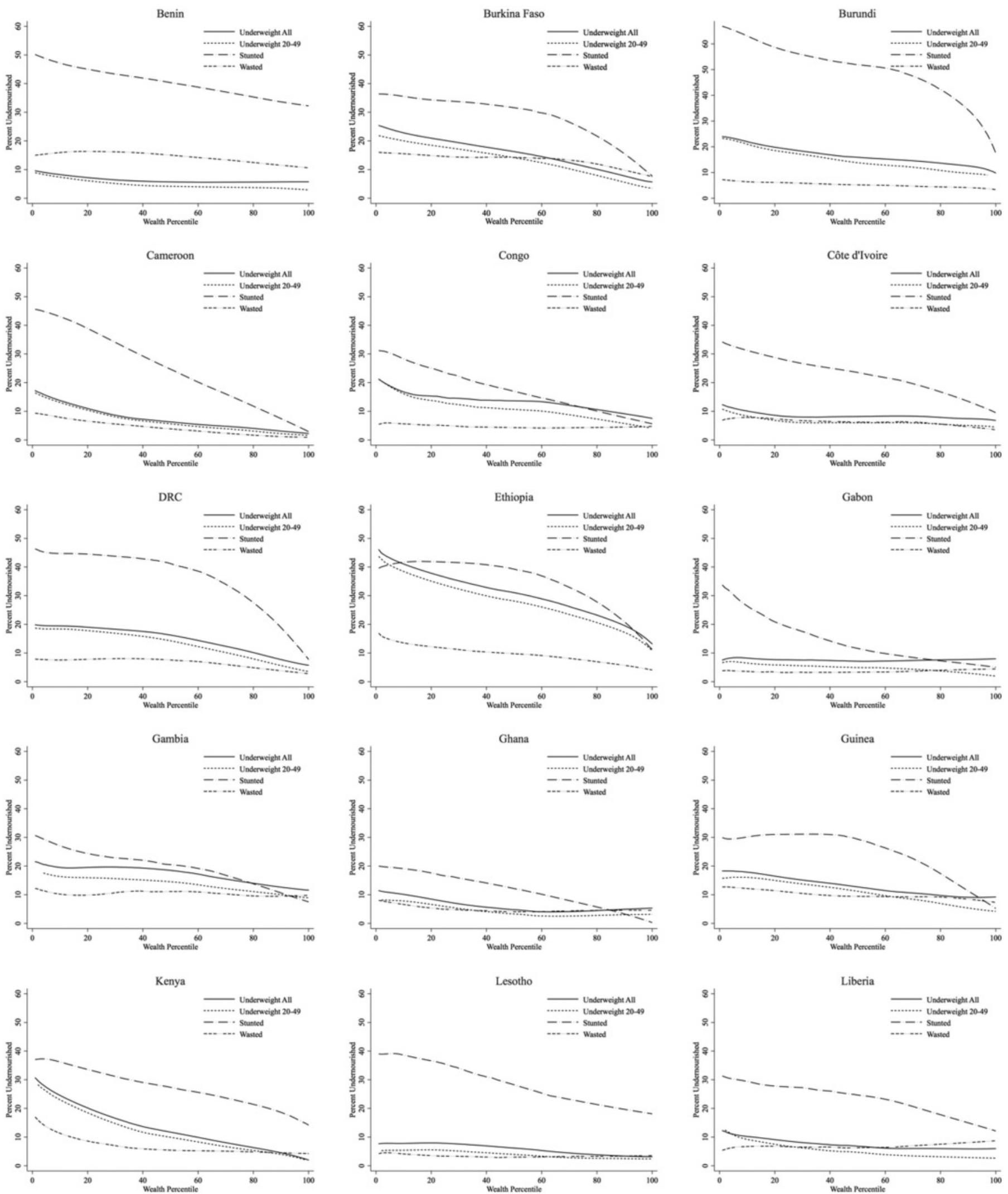
636

THE REVIEW OF ECONOMICS AND STATISTICS
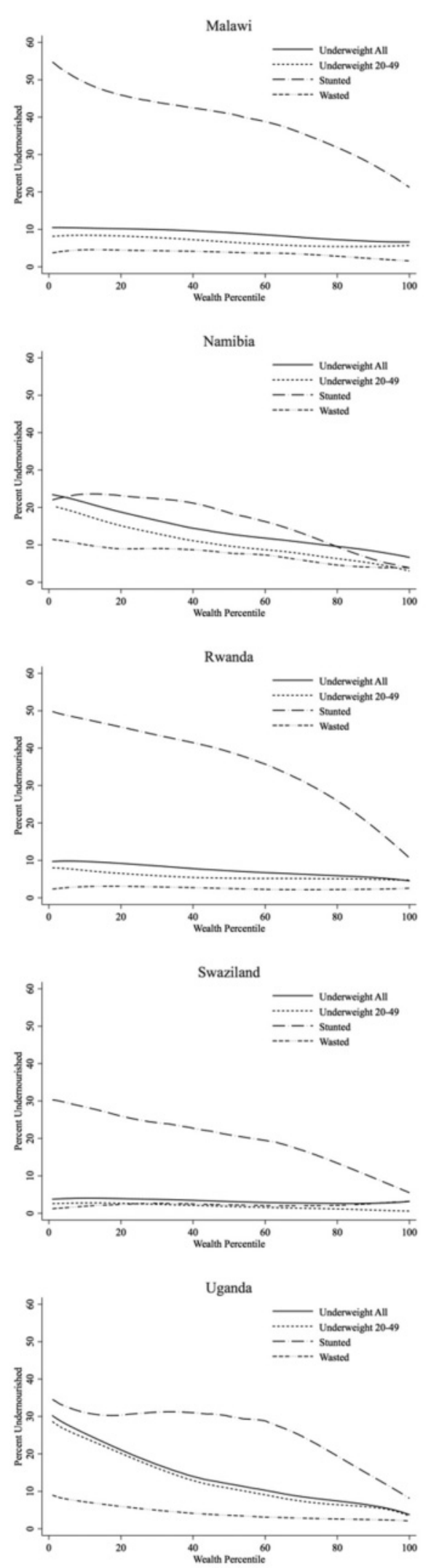

Figure 1. -CONTINUED.
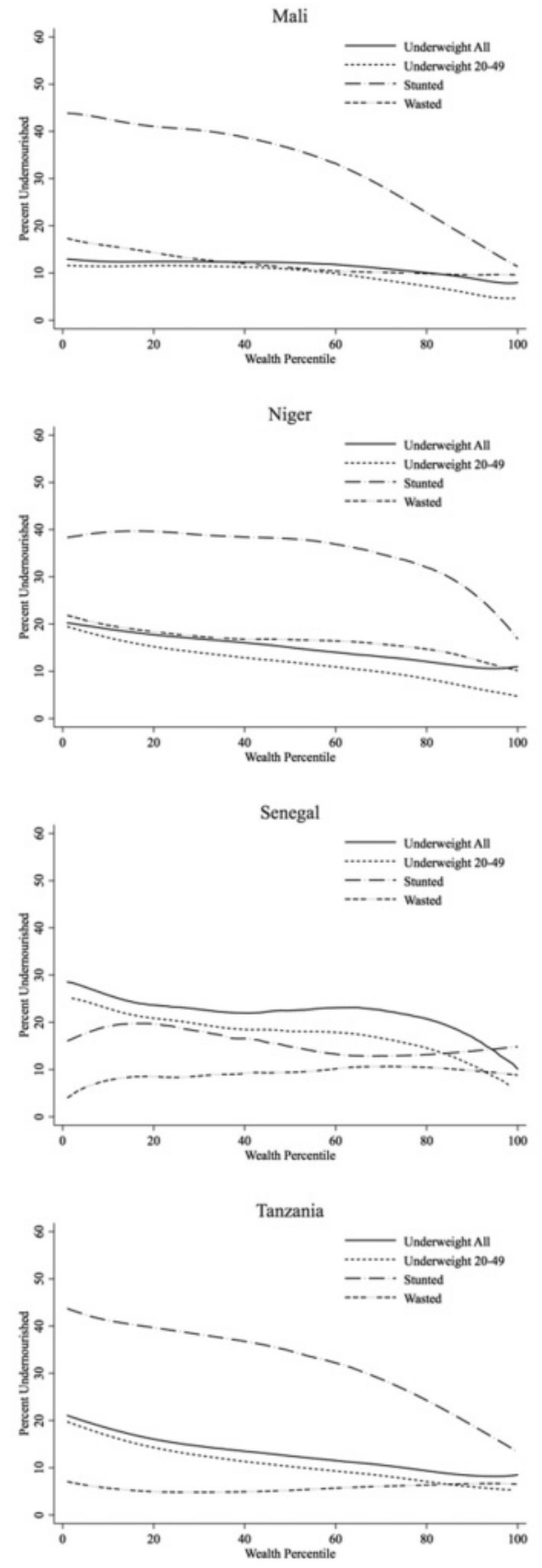

Zambia

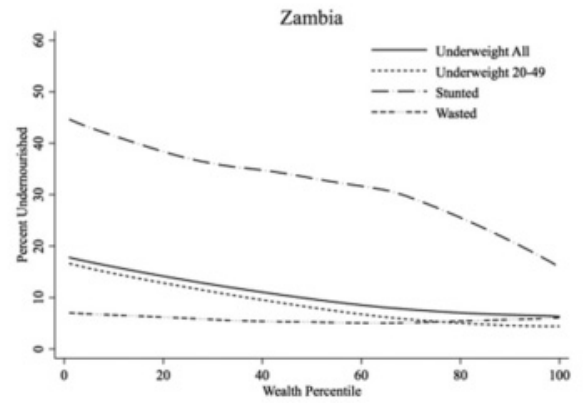

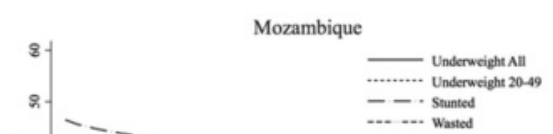
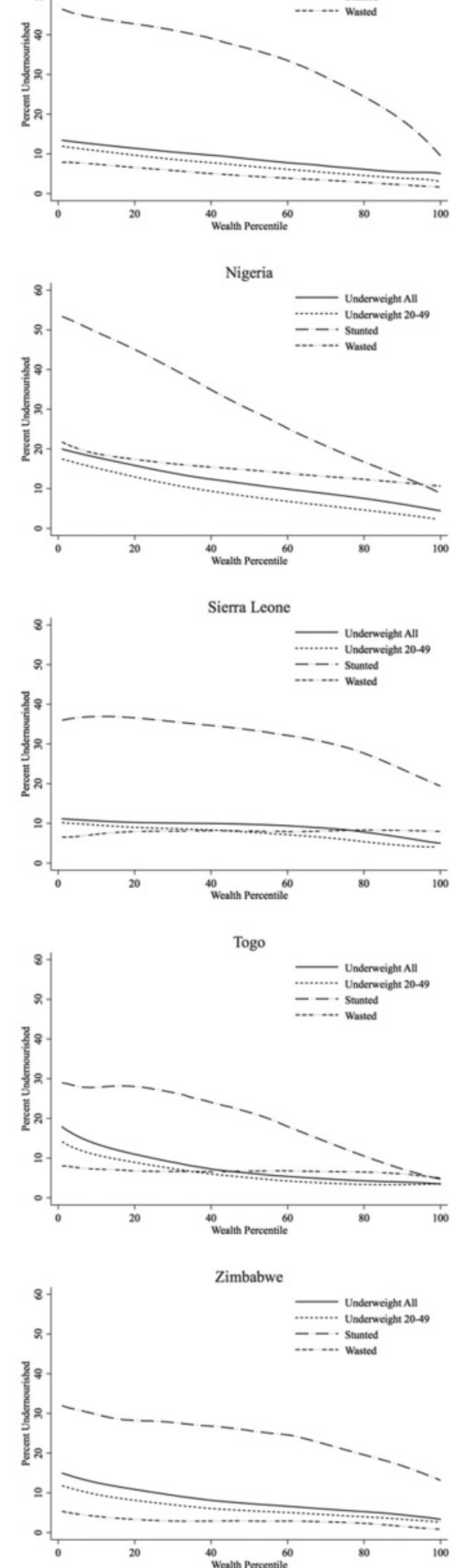

The graphs show proportions of underweight women and stunted and wasted children (aged between 0 and 5) across the distribution of household wealth percentiles. Data are drawn from the DHS. Observations with missing values for either household wealth or nutritional outcomes and pregnant women have been dropped. The solid line represents women aged 15 through 49 ; the dashed line, women aged 20 through 49 .
Households are ranked by their wealth index and placed into wealth percentiles. A Lowers regression is used to fit the lines. 
and height-for-age and weight-for-height $z$-scores for children) on the wealth index, which (as noted) is also a $z$-score. The regression coefficient gives the number of standard deviations of the nutritional indicator attributed to a 1 standard deviation increase in wealth. The supplement gives results by country using the DHS and the analogous results using standardized consumption $z$-scores from the LSMS. The estimated wealth effects are statistically significant in almost all cases (the exceptions are for child wasting in a few countries). For women's BMI, the mean regression coefficient is 0.26 , while it is 0.30 for the height-for-age $z$-score and only 0.09 for weight-for-height. (The supplement gives the coefficients separately for boys and girls; the results are similar, with no clear pattern in evidence.) For the countries where the wealth effect on child stunting is highest (Burundi, Cameroon, and Nigeria), a 1 standard deviation increase in wealth is associated with a 0.5 standard deviation increase in the incidence of child stunting. For about half the countries, the wealth effect on stunting is less than 0.3 standard deviations. The overall incidence of undernutrition makes little difference to the results; countries with a low incidence of undernutrition do not have stronger or weaker wealth effects relative to countries with a high incidence of undernutrition.

However, these results cannot tell us much about the efficacy of household wealth as a tool to reach undernourished individuals. Low-wealth effects need not imply that the incidence of undernutrition is unresponsive to income or wealth differences (Ravallion, 1990). Moreover, even if household wealth and individual nutritional status are correlated, it does not follow that a large proportion of undernourished individuals will be found in the lower ends of the wealth distribution; the supplement demonstrates this point in a simple theoretical model.

\section{B. Conditional and Joint Probabilities}

Concentration curves - the cumulative share of undernourished individuals by cumulative household wealth percentile ranked from the poorest up-exhibit marked concavity for some countries, notably Cameroon, for all three indicators; Congo, Gabon, and Ghana, for stunting; and Gabon, Kenya, Uganda, Zambia, and Zimbabwe, for underweight women (see the supplement). This suggests that in these countries, undernourished individuals tend to be concentrated in the poorer strata of household wealth. However, in most cases the curves tend to be fairly close to the diagonal line.

We focus on the points on the concentration curves corresponding to the poorest $20 \%$ and $40 \%$ of the household wealth index. Table 3 presents the proportion of undernourished women and children that falls into the bottom $20 \%$ and $40 \%$ of the household wealth distribution. These are the estimated values of $\operatorname{Pr}(w<1 \mid n<1)$ where the nutritional attainments of an individual are denoted $n$ and the wealth of the household to which the individual belongs is $w$, both normalized by appropriate cutoff points (stipulated nutritional thresholds or poverty lines). The supplement also gives the reverse probabilities $(\operatorname{Pr}[n<1 \mid w<1])$. Given the wealth effect on nutritional status, the values for underweight women and stunted children are generally bounded below by $\operatorname{Pr}(w<1)$ (either 0.2 or 0.4$)$. The only exceptions are for underweight women in Côte D'Ivoire, Gambia (for poorest 20\%), and Gabon (for poorest 40\%) and child wasting in Gambia, Senegal, Sierra Leone, and Swaziland, where the wealth effect is not evident (see the supplement).

What is striking about the results in table 3 is how close the conditional probabilities are to $\operatorname{Pr}(w<1)$. For 25 of the 30 countries, less than $30 \%$ of underweight women are found in the poorest $20 \%$ of households. This is true for 18 and 21 countries with regard to stunted and wasted children (respectively). On average, roughly three-quarters of underweight women and undernourished children are not found in the poorest $20 \%$ of households when judged by household wealth. And about half of the underweight women and undernourished children are not found in the poorest $40 \%$.

Considering the reverse conditional probability-the proportion of individuals in poor households who are undernourished-we find that only $16 \%$ of women in the poorest $20 \%$ of households are underweight on average and $10 \%$ of children are wasted. A larger proportion of children are stunted, at around $40 \%$ on average. (See the supplement for full results by country.) Among the poorest $40 \%$ of households, we find similar (although slightly lower) numbers.

We also did a breakdown of the conditional probabilities for stunting and wasting by gender (see the supplement). Stunted and wasted girls are slightly more likely to be found in the bottom $20 \%$ and $40 \%$ of household wealth than boys overall. There is some variation across countries, though the gender differences are generally small.

We further calculated the conditional probabilities for severely stunted and wasted children, where severe stunting is defined as 3 or more standard deviations below the median height-for-age and weight-for-height $z$-scores, respectively. Compared to table 3 , we find that severely stunted children are more likely to be found in the poorest $20 \%$ and $40 \%$ of households. While on average, $29 \%$ of stunted children are in the poorest wealth quintile, this rises to $32 \%$ for severely stunted children and from 55\% to 59\% for the bottom two quintiles (full results can be found in the supplement). There is little difference with table 3 for severely wasted children.

The countries with a higher percentage of undernourished women in the poorest strata of households also tend to have a higher proportion of wasted children in that group; the correlation coefficients are 0.62 and 0.64 for the poorest $20 \%$ and $40 \%$, respectively. This is also true for stunted children, although the corresponding correlations are somewhat weaker at 0.33 and 0.43 . In only three countries (Cameroon, Ghana, and Kenya) are more than $30 \%$ of nutritionally deprived individuals found in the poorest $20 \%$ for all three nutritional indicators.

Table 4 provides the same statistics using the consumption indicator, with similar results. Overall, $70 \%$ of undernourished women and children are not found in the poorest $20 \%$ 
Table 3.-Proportion of Undernourished Individuals Who Fall into the Poorest $20 \%$ and $40 \%$ of the Household Wealth Distribution

\begin{tabular}{|c|c|c|c|c|c|c|}
\hline & \multicolumn{3}{|c|}{ Poorest $20 \%$ of Households } & \multicolumn{3}{|c|}{ Poorest $40 \%$ of Households } \\
\hline Benin & 0.249 & $0.246^{*}$ & 0.231 & 0.440 & $0.471^{*}$ & 0.486 \\
\hline Burundi & 0.260 & $0.225^{*}$ & 0.261 & 0.438 & $0.436^{*}$ & 0.467 \\
\hline Cameroon & 0.364 & $0.405^{*}$ & 0.485 & 0.603 & 0.682 & 0.738 \\
\hline Congo & 0.201 & 0.371 & 0.278 & 0.431 & 0.597 & 0.508 \\
\hline Côte d'Ivoire & 0.197 & $0.335^{*}$ & 0.312 & 0.374 & 0.590 & 0.494 \\
\hline Gabon & 0.220 & 0.518 & 0.293 & 0.368 & 0.715 & 0.440 \\
\hline Gambia & 0.174 & 0.250 & 0.175 & 0.424 & 0.508 & 0.413 \\
\hline Ghana & 0.355 & 0.433 & 0.358 & 0.615 & 0.723 & 0.489 \\
\hline Guinea & 0.257 & $0.234^{*}$ & 0.304 & 0.467 & 0.538 & 0.538 \\
\hline Kenya & 0.318 & $0.368^{*}$ & 0.496 & 0.592 & 0.615 & 0.670 \\
\hline Lesotho & 0.249 & $0.380 *$ & 0.445 & 0.558 & 0.632 & 0.639 \\
\hline Niger & 0.225 & $0.206^{*}$ & 0.239 & 0.438 & 0.434 & 0.412 \\
\hline Nigeria & 0.288 & $0.358^{*}$ & 0.285 & 0.526 & 0.641 & 0.526 \\
\hline Rwanda & 0.243 & $0.275^{*}$ & 0.254 & 0.453 & 0.524 & 0.503 \\
\hline Senegal & $0.195^{*}$ & 0.370 & 0.318 & 0.355 & 0.730 & 0.543 \\
\hline Sierra Leone & 0.207 & $0.262^{*}$ & 0.171 & 0.399 & 0.501 & 0.404 \\
\hline Swaziland & 0.268 & $0.349^{*}$ & 0.266 & 0.489 & 0.603 & 0.522 \\
\hline Tanzania & 0.290 & $0.277^{*}$ & 0.299 & 0.502 & 0.541 & 0.485 \\
\hline Togo & 0.360 & $0.349^{*}$ & 0.285 & 0.610 & 0.675 & 0.539 \\
\hline Uganda & 0.327 & $0.241^{*}$ & 0.295 & 0.604 & 0.489 & 0.602 \\
\hline Zambia & 0.259 & $0.294^{*}$ & 0.273 & 0.480 & 0.542 & 0.531 \\
\hline Zimbabwe & 0.283 & $0.288^{*}$ & 0.284 & 0.514 & 0.528 & 0.513 \\
\hline Mean & 0.254 & $0.293^{*}$ & 0.278 & 0.478 & 0.548 & 0.515 \\
\hline
\end{tabular}

The table gives proportions of underweight women and stunted and wasted children who fall into the bottom 20th and 40th percentiles of the household wealth distribution. For example, $24.9 \%$ of underweight women live in households in the bottom 20th percentile of household wealth in Benin. Cases marked with an asterisk are those in which the undernutrition rate exceeds the corresponding wealth poverty rate, implying that the conditional probability has an upper bound less than unity when all of the wealth poor are undernourished. Data are drawn from DHS. Means are population weighted.

Table 4.-Proportion of Undernourished Individuals Who Fall into the Poorest 20\% and 40\% of the Household Consumption PER CAPITA DISTRIBUTION

\begin{tabular}{|c|c|c|c|c|c|c|c|c|c|c|}
\hline & \multicolumn{3}{|c|}{ Poorest $20 \%$ of Households } & \multicolumn{3}{|c|}{ Poorest $40 \%$ of Households } & \multicolumn{3}{|c|}{ Poorest Households by Poverty Rate } & \multirow[b]{2}{*}{$\begin{array}{l}\text { Poverty } \\
\text { Rate }\end{array}$} \\
\hline & $\begin{array}{l}\text { Underweight } \\
\text { Women }\end{array}$ & $\begin{array}{l}\text { Stunted } \\
\text { Children }\end{array}$ & $\begin{array}{c}\text { Wasted } \\
\text { Children }\end{array}$ & $\begin{array}{l}\text { Underweight } \\
\text { Women }\end{array}$ & $\begin{array}{c}\text { Stunted } \\
\text { Children }\end{array}$ & $\begin{array}{c}\text { Wasted } \\
\text { Children }\end{array}$ & $\begin{array}{l}\text { Underweight } \\
\text { Women }\end{array}$ & $\begin{array}{c}\text { Stunted } \\
\text { Children }\end{array}$ & $\begin{array}{c}\text { Wasted } \\
\text { Children }\end{array}$ & \\
\hline Burkina Faso & & 0.354 & 0.308 & & 0.599 & 0.556 & & 0.749 & 0.725 & 0.553 \\
\hline Ghana & 0.365 & 0.471 & 0.393 & 0.575 & 0.695 & 0.640 & 0.431 & 0.553 & 0.472 & 0.253 \\
\hline Malawi & & 0.254 & 0.280 & & 0.504 & 0.471 & & 0.760 & 0.755 & 0.709 \\
\hline Nigeria & & 0.258 & 0.306 & & 0.503 & 0.599 & & 0.627 & 0.728 & 0.535 \\
\hline Mean & 0.319 & 0.323 & 0.324 & 0.558 & 0.555 & 0.564 & 0.602 & 0.545 & 0.554 & 0.418 \\
\hline
\end{tabular}

The table gives proportions of underweight women, and stunted and wasted children who live in households ranked in the bottom 20th and 40th percentiles of the household consumption per capita distribution, along with proportions who live in households with per capita consumption below the poverty line of $\$ 1.90$ per day. Data are drawn from LSMSs. Means are population weighted.

of households based on consumption per person, while almost half of them are not found in the poorest $40 \%$. Table 4 also lists the proportions of undernourished women and children found in households deemed poor using the poverty rate of $\$ 1.90$ per day. The pattern is similar to our findings using the wealth rankings, with conditional probabilities only slightly higher than the national poverty rates in many cases. Unsurprisingly, the higher the poverty rate, the higher the proportion of undernourished who are found in the poorest $x \%$ of households.
We use the fact that $\operatorname{Pr}(n<1, w<1)=\operatorname{Pr}(w<1 \mid n<$ 1) $\operatorname{Pr}(n<1)$ and combine tables 1 and 3 to infer the joint probabilities of being both undernourished and wealth poor. The mean empirical values for the DHS data are given in table 5; the supplement provides the country-specific values. For underweight women and the poorest $20 \%$, the joint probability is under 0.04 for 25 countries. The mean joint probability of a woman being underweight and living in the poorest $20 \%$ of households is only 0.03 , rising to 0.05 for the poorest $40 \%$. For child wasting, the probabilities are even lower 
Table 5.-Mean Joint Probabilities of Being Undernourished and Wealth Poor

\begin{tabular}{|c|c|c|c|c|c|c|}
\hline & \multicolumn{3}{|c|}{ Poorest $20 \%$ of Households } & \multicolumn{3}{|c|}{ Poorest $40 \%$ of Households } \\
\hline & Underweight Women & Stunted Children & Wasted Children & Underweight Women & Stunted Children & Wasted Children \\
\hline Mean joint probability & 0.029 & 0.095 & 0.024 & 0.054 & 0.177 & 0.045 \\
\hline Correlation coefficient & 0.890 & 0.740 & 0.891 & 0.937 & 0.905 & 0.966 \\
\hline \multirow[t]{2}{*}{ Elasticity of joint to marginal } & 0.858 & 0.532 & 0.850 & 0.906 & 0.680 & 0.931 \\
\hline & $(0.079)$ & $(0.086)$ & $(0.079)$ & $(0.063)$ & $(0.053)$ & $(0.045)$ \\
\hline
\end{tabular}

The first row of numbers gives the population-weighted mean joint probabilities of being both undernourished and wealth-poor across the thirty countries. Wealth percentiles are created at the household level. The correlation coefficients (second row) are between the joint probabilities and the relevant undernutrition rates from table 1. Elasticities (third row) are the regression coefficients of the log joint probability on the log marginal probabilities, with robust standard errors in parentheses.

Figure 2.-Countries with Fewer Undernourished Individuals Tend to Have a Higher Proportion of Those Individuals in Wealth-Poor Households
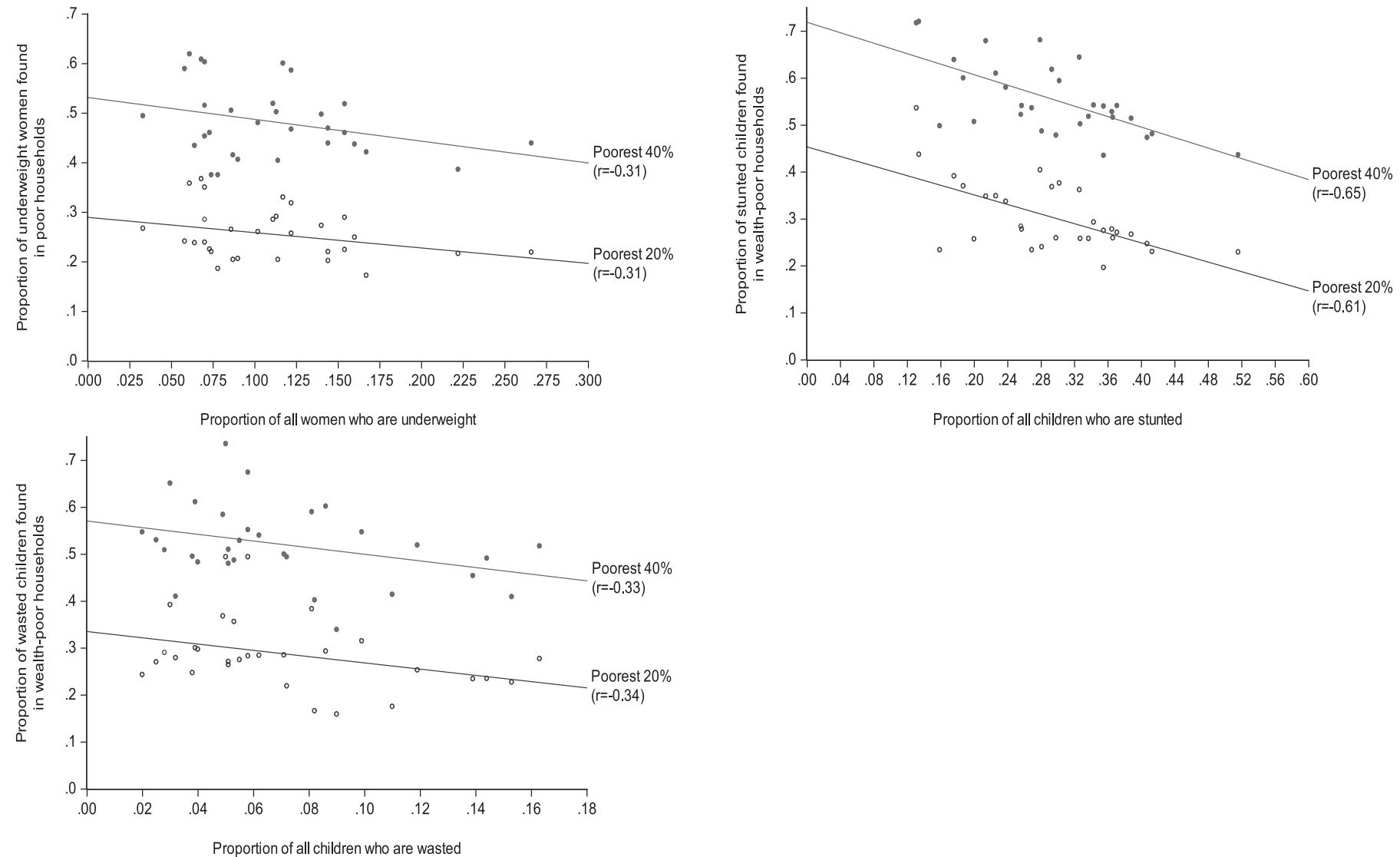

The graph plots the conditional probability of a woman or child being both undernourished and in a poor household against the share of undernourished women and children for each country. The actual values are given in tables 1 and 3 .

than for underweight women, at under 0.02 for two-thirds of all countries. The joint probabilities are higher for stunting, with a mean of 0.10 and 0.18 for the poorest $20 \%$ and $40 \%$, respectively.

The joint probabilities tend to be positively correlated with the marginal probability of being undernourished; the bottom row of table 5 gives the correlation coefficients. The table also gives the OLS elasticities across countries (regression coefficients of the log joint probability on the log marginal probabilities). The elasticities are all less than unity, implying that a higher rate of undernutrition should reduce the conditional probability. On balance, we do find that countries with a higher overall incidence of undernutrition tend to have a higher share of these disadvantageous outcomes among the "nonpoor" based on wealth. Figure 2 plots the values from tables 1 and 3 for the incidence of undernutrition for women and children, highlighting the negative relationship between the joint and marginal probabilities; the relationship is strongest for stunting and much weaker for underweight women and stunted children).

These results suggest that when relatively few women or children are undernourished, one tends to find them more concentrated in relatively poorer households. Conversely, when there are many undernourished women and children, one tends to find them more widely spread across the household wealth distribution. From a policy perspective, these results 
suggest that targeting relatively poor households will tend to work less well in reaching vulnerable women and children in countries where the overall problem of undernutrition is greater. $^{18}$

\section{Explanations}

We comment on a number of possible explanations for our findings.

\section{A. Demographics of the Poverty Profile}

It might be conjectured that a demographic imbalance between wealth fractiles is playing a role in our findings, given that poorer households are often found to include more children. To account for the possibility that children (and possibly women) are distributed unevenly across the household wealth distribution, we recalculate wealth percentiles by balancing the demographic composition separately for women and children. In other words, we rank all children (and similarly women) according to their household wealth and create wealth percentiles such that $x \%$ of children fall into the bottom $x \%$ of the wealth distribution. We call this the demographically balanced wealth distribution.

We find that the conditional probabilities using the demographically balanced wealth fractiles are very similar to those seen in table 3 (see the supplement). On average, a slightly higher proportion of undernourished women are located in the poorest $20 \%$ and $40 \%$ of the individual relative to the household wealth distribution. The opposite is found for stunted and wasted children (although this varies across countries), suggesting that poorer households do contain a higher proportion of stunted and wasted children, though the difference is not large. The supplement gives the joint probabilities, with similar findings. We conclude that demographic imbalance is not an important factor in explaining our results.

\section{B. Selective Child Mortality}

About $10 \%$ of children born in sub-Saharan Africa die before they reach 5 years of age. It is also known that mortality rates tend to be higher for poorer families. ${ }^{19}$ There have been some studies of the effects of such selective mortality (also called "survivor bias") on various measures, although the effects documented have tended to be small (Boerma, Sommerfelt, \& Bicego, 1992; Bozzoli, Deaton, \& QuintanaDomeque, 2007; Alderman, Lokshin, \& Radykin, 2011).

\footnotetext{
${ }^{18}$ This is also evident in the data for stunting in Africa assembled by Bredenkamp, Buisman, and Van de Poel 2014; (see the Africa data points in their figure 1), although across all developing countries, they find that inequalities in stunting are greater in countries where stunting is more prevalent. Evidently Africa is different in this respect, though the reason is unclear.

${ }^{19}$ See, for example, UNICEF (2011, figure 7). Ravallion (2016) reviews past studies on the socioeconomic differentials in child mortality.
}

How much are our results on the conditional probabilities in table 3 likely to have been affected by selective child mortality?

We do not, of course, know what the nutritional status of the children who died would have been had they lived. Child mortality is clearly more likely when children are undernourished, whether living in a poor household or not. We assume that all those who died (whether living in poor households or not) were undernourished. This is not likely to strictly hold, but it seems the most reasonable assumption to make in this context. Naturally, child deaths among the undernourished living in nonpoor households will counteract to some extent the effect of selective mortality on the probability of living in a poor household given that one is undernourished. Under this assumption one can readily derive the following formula for the counterfactual conditional probability without child mortality:

$$
\begin{aligned}
& \operatorname{Pr}^{*}(w<1 \mid n<1) \\
& =\frac{\operatorname{Pr}(w<1 \mid n<1) \operatorname{Pr}(n<1)+M(w<1) \operatorname{Pr}(w<1)}{\operatorname{Pr}(n<1)+M} .
\end{aligned}
$$

Here $M=C M R /(1-C M R)$ is the ratio of recorded child deaths to the number of live children, where $C M R$ is the overall child mortality rate (as a proportion of live births), while $M(w<1)$ is the corresponding odds ratio for poor households.$^{20}$ Selective mortality here means that $M(w<1)>M$. Also, $\operatorname{Pr}(w<1)$ is defined as the poverty rate for children (the proportion of children under 5 living in poor households). From equation (1) we can see that $\operatorname{Pr}^{*}(w<1 \mid n<1)>$ $\operatorname{Pr}(w<1 \mid n<1)$ if and only if $M(w<1) / M>\operatorname{Pr}^{*}(w<$ $1 \mid n<1) /(\operatorname{Pr}(w<1)$. It is thus an empirical question as to whether selective mortality increases the conditional probability under our assumptions.

The DHS records a list of children who died between birth and 5 years of age. We use these data, along with the household and mother characteristics, to evaluate equation (1). Averaged over 29 countries, ${ }^{21}$ we find $M=0.123$. For the poorest $20 \%$, we obtain $M(w<1)=0.136$ and $\operatorname{Pr}(w<1)=0.220$; for the poorest $40 \%$, the corresponding values are 0.133 and 0.439 . Using our data, we find that the counterfactual conditional probability for child stunting is 0.28 , as compared to 0.29 in table 3 . For the poorest $40 \%$, the estimated counterfactual conditional probability is 0.53 , as compared to 0.55 (table 3 ). For child wasting, the mean counterfactual probabilities of 0.26 and 0.49 are similar to those in table 3 for the poorest $20 \%$ and $40 \%$, respectively. Under our assumptions, we do not find that selective mortality is attenuating the conditional probability of interest.

\footnotetext{
${ }^{20}$ The odds ratio appears here because child mortality rates are usually expressed as a proportion of live births.

${ }^{21}$ Child mortality information is not available for Senegal.
} 
Table 6.-Conditional Probabilities with AND Without InTRahousehold Inequality for the Poorest 20\% of Households

\begin{tabular}{|c|c|c|c|c|c|c|c|c|c|}
\hline & \multicolumn{3}{|c|}{$\begin{array}{l}\text { Underweight (actual and simulated without } \\
\text { intrahousehold inequality) }\end{array}$} & \multicolumn{3}{|c|}{$\begin{array}{l}\text { Stunted (actual and simulated without } \\
\text { intrahousehold inequality) }\end{array}$} & \multicolumn{3}{|c|}{$\begin{array}{l}\text { Wasted (actual and simulated without } \\
\text { intrahousehold inequality) }\end{array}$} \\
\hline & Actual & Regular Cutoff & New Cutoff & Actual & Regular Cutoff & New Cutoff & Actual & Regular Cutoff & New Cutoff \\
\hline \multicolumn{10}{|l|}{ Poorest $20 \%$} \\
\hline Ethiopia & 0.226 & 0.259 & 0.260 & 0.272 & 0.275 & 0.271 & 0.287 & 0.295 & 0.298 \\
\hline Ghana & 0.375 & 0.437 & 0.439 & 0.445 & 0.420 & 0.453 & 0.343 & 0.320 & 0.301 \\
\hline Lesotho & 0.243 & 0.304 & 0.311 & 0.361 & 0.357 & 0.347 & 0.395 & 0.528 & 0.478 \\
\hline Namibia & 0.294 & 0.382 & 0.398 & 0.383 & 0.434 & 0.422 & 0.387 & 0.293 & 0.356 \\
\hline Rwanda & 0.235 & 0.287 & 0.264 & 0.273 & 0.279 & 0.274 & 0.256 & 0.274 & 0.218 \\
\hline Senegal & 0.184 & 0.267 & 0.210 & 0.318 & 0.376 & 0.364 & 0.224 & 0.286 & 0.242 \\
\hline Sierra Leone & 0.203 & 0.269 & 0.277 & 0.253 & 0.254 & 0.252 & 0.182 & 0.160 & 0.177 \\
\hline Mean & 0.229 & 0.276 & 0.272 & 0.291 & 0.295 & 0.293 & 0.270 & 0.276 & 0.269 \\
\hline \multicolumn{10}{|l|}{ Poorest $40 \%$} \\
\hline Ethiopia & 0.454 & 0.525 & 0.521 & 0.527 & 0.533 & 0.520 & 0.591 & 0.619 & 0.611 \\
\hline Ghana & 0.621 & 0.658 & 0.699 & 0.708 & 0.698 & 0.711 & 0.489 & 0.453 & 0.447 \\
\hline Lesotho & 0.521 & 0.593 & 0.585 & 0.617 & 0.614 & 0.617 & 0.588 & 0.668 & 0.600 \\
\hline Namibia & 0.499 & 0.611 & 0.638 & 0.652 & 0.685 & 0.661 & 0.579 & 0.483 & 0.562 \\
\hline Rwanda & 0.455 & 0.542 & 0.546 & 0.525 & 0.534 & 0.524 & 0.495 & 0.538 & 0.503 \\
\hline Senegal & 0.379 & 0.541 & 0.419 & 0.589 & 0.624 & 0.636 & 0.468 & 0.508 & 0.533 \\
\hline Sierra Leone & 0.394 & 0.519 & 0.485 & 0.491 & 0.493 & 0.482 & 0.417 & 0.442 & 0.481 \\
\hline Mean & 0.449 & 0.538 & 0.519 & 0.545 & 0.550 & 0.542 & 0.526 & 0.549 & 0.549 \\
\hline
\end{tabular}

The table gives proportions of underweight women and stunted and wasted children who fall into the bottom 20th and 40th percentiles of the household wealth distribution. Data are drawn from DHS that collected BMI for male adults as well as for women and children. "Actual" calculates conditional probabilities using the actual values for individual nutritional outcomes. To simulate the results without intrahousehold inequality, all household members are assigned the household's average value of BMI, height-for-age and weight-for-height for adults and children, respectively. With the "regular" cutoff, individuals are assigned to be underweight, stunted, and wasted if this value is below 18.5 for BMI and -2 for height-for-age and weight-for-height. With the "new cutoff," a cutoff point for undernourishment is chosen to minimize the difference between average rate of undernourishment and simulated nourishment. This cutoff is always above that of the standard cutoff points. Wealth percentiles are household based. Statistics are population weighted.

\section{Measurement Error in Nutritional Outcomes}

Another potential explanation for the results is measurement error in the nutritional outcomes. This could be a particular concern for very young children, for which accurate anthropometric measurement can be difficult (Ulijaszek \& Kerr, 1999; Larsen, Headey, \& Masters, 2017; Agarwal et al., 2017). We reestimate the conditional probabilities for stunting and wasting for children 18 months and older only. We find very similar results to table 3 ; on average, only $29 \%$ of stunted children and $28 \%$ of wasted children 18 months and over are found in the poorest $20 \%$ of households (see the supplement).

We further consider the relationship between nutritional outcomes for mothers and their children. If measurement error in outcomes is confounding the results, we might expect the relationship to be quite weak. We first look at the difference in means for both height-for-age and weight-for-height $z$-scores for children with and without underweight mothers and find that children whose mothers are underweight have significantly lower height-for-age and weight-for-height $z$-scores across almost all countries (see the supplement). Correlation coefficients between mothers' BMI and child height-for-age and weight-for-height $z$-scores are positive and significant at the $5 \%$ level for all countries except Lesotho and Sierra Leone (see the supplement). While measurement error in nutritional outcomes may be a factor, it is unlikely to fully explain our results.

\section{Intrahousehold Inequality in Nutritional Status}

Using the DHS data with anthropometrics for all adults and children, we observe substantial inequality within the household in terms of nutritional outcomes: on average across countries, almost a quarter of household members are found to be undernourished. ${ }^{22}$ How much does this intrahousehold inequality in nutritional status contribute to the seemingly low conditional probabilities that we have found (such as in table 3)? A straightforward way to assess this is to recalculate the conditional probabilities using artificial distributions in which we replace the measured BMI of each adult by the household mean BMI, and similarly for children's z-scores. That is, every adult and child within the household has the same nutritional status. ${ }^{23}$

Table 6 gives the results. The column "actual" refers to the calculated conditional probability from the original data. The numbers under "regular cutoff" are the corresponding probabilities when we reassign each adult the household mean BMI and for each child as well. Given that the distribution functions are not linear, equalizing the nutritional status within households does not ensure that the overall rate of undernutrition is unchanged, so the numbers in the "regular cutoff" column may be affected by the change in the mean undernutrition rate. To account for this we also give estimates under "new cutoff," in which we adjust the nutritional thresholds to balance the overall rate of undernutrition. In almost all cases, we find that the conditional probabilities are higher when we artificially eliminate intrahousehold inequality. ${ }^{24}$ However,

\footnotetext{
${ }^{22}$ We include adults between ages 15 and 49 and children 5 years and younger for which anthropometric outcomes are available.

${ }^{23}$ Note that while we have eliminated inequality between adults and children within the household, it still remains that adults and children may have different nutritional outcomes. If the differences between adults and children are large, our results will underestimate the true impact of intrahousehold inequality.

${ }^{24}$ For Ethiopia and Senegal, the undernutrition rate for women exceeds $20 \%$ (table 1 ). For them, the conditional probability cannot exceed 0.75 and 0.90 . Even so, it remains clear that only a small share of the gap between the
} 
Figure 3.-Health Outcomes for Children and Household Wealth

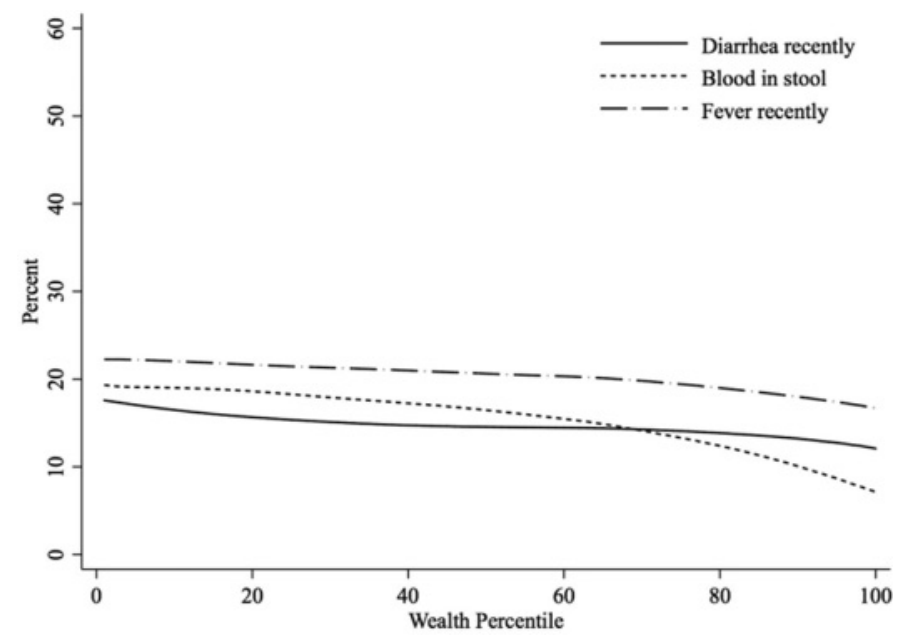

The graph shows the proportion of children aged between 0 and 5 who have suffered diarrhea in the past two weeks, the proportion with diarrhea who have had blood in their stool, and the proportion who have had a fever in the past two weeks across the distribution of household wealth percentiles aggregated across countries. Data are drawn from DHS. Households are ranked by their wealth index and placed into country-level wealth percentiles. A lowess regression is used to fit the lines.

the effect is modest. ${ }^{25}$ For example, the conditional probabilities for underweight women in the bottom $20 \%$ of household wealth increase (on average) from 0.23 to 0.28 using the regular cutoff. For children, the effect is negligible: for child stunting, the difference is 0.29 to 0.30 (and 0.27 to 0.28 for wasting). While intrahousehold inequality in nutritional status does lower the conditional probabilities, particularly among women, it is clear that other factors are in play.

\section{E. Common Health Risks}

It is known that health shocks often impede nutritional absorption. While it is likely that higher household wealth can help parents protect their children from health risks, there are clear limits, leaving locally covariate health risks facing children in nonpoor families. The DHS provide some useful clues to the extent of these common health risks and whether they can help explain our findings. For children under age 5, figure 3 plots the incidence of reported diarrhea in the past two weeks, the incidence of blood in the stool (when diarrhea is reported), and the incidence of fever in the past two weeks (results at the country-level can be found in the supplement). While there are signs of a wealth effect in most cases, it is clearly not strong. Even children in the high-wealth groups appear to have significant exposure to disease (though still less than for the poorest). Health risks are clearly spread quite widely across the distribution of households in all countries studied, which is likely to be a contributing factor in our results on the conditional probabilities.

estimated conditional probability and its maximum value can be attributed to intra-household inequality.

${ }^{25}$ The conditional probabilities under the "actual" column will differ slightly from those in table 3 due to differing samples used in calculations.

\section{F. Wealth Measurement Errors}

The fact that our results are robust to using consumption from LSMS surveys goes some way toward relieving concerns about measurement errors in the DHS wealth index. Here we also ask how much our results change on introducing other household- and individual-level factors that can be expected to enhance power for predicting individual outcomes and enhance targeting capability, such as education and labor assets. For this, we estimate augmented regressions that can be expected to perform similarly to the widely used proxy means test (PMT) method based on the predicted values of regressions calibrated to survey data (Brown, Ravallion, \& van de Walle, 2018). Of course, errors remain, though they are likely to also remain in the targeted policies.

The first model we consider regresses nutritional outcomes on the wealth index and other household-level variables:

$$
y_{i j m}=\alpha_{m}+\beta_{m} w_{j m}+\gamma_{m} x_{j m}+\varepsilon_{i j m},
$$

where $y_{i j m}$ is the anthropometric index for individual $i$ in household $j$ in country $m$, and $w_{j m}$ is the wealth index. The vector $x_{j m}$ includes the separate components of the wealth index to help address possible concerns with the weights used in its construction; for example, the index may not adequately adjust for economies of scale in consumption. It also includes other household-level variables, such as size and composition, and characteristics of the head. Dummies for survey month and region of residence are also entered as controls. Model 2 adds the observable individual-level variables, $z_{i j m}$ :

$$
y_{i j m}=\alpha_{m}+\beta_{m} w_{j m}+\gamma_{m} x_{j m}+\delta_{m} z_{i j m}+\varepsilon_{i j m} .
$$

For the incidence of underweight women, age, education, and marital status are added. For example, mother's education is likely to be an important factor, especially through knowledge about nutrition and health care. ${ }^{26}$ For children, age, gender, and characteristics of the child's mother are included. To avoid ad hoc functional form assumptions, age, education, and household size are broken into categories, each of which is entered as a dummy variable. OLS is used to estimate each model, with standard errors clustered at the PSU level.

Table 7 presents the results for models 1 and 2 for underweight women and undernourished children. The table gives the mean proportion of undernourished individuals who fall into the poorest $20 \%$ and $40 \%$ of the distribution of the predicted values based on wealth and (unlike prior tables) the additional covariates. ${ }^{27}$ (The supplement gives the results by country.) We find that on average, $31 \%$ of underweight

\footnotetext{
${ }^{26}$ Recent research has argued that widows and remarried women often fare poorly when compared to married-once women (Anderson \& Ray, forthcoming; Djuikom \& van de Walle, 2018).

${ }^{27}$ As in Brown et al. (2018), with household consumption, we find that the proportion of individuals predicted to be undernourished is far less than the actual rate of undernourishment. To account for this, we sort individuals into percentiles based on their predicted value from the regressions. We assign individuals with a percentile at or below the rate of
} 
Table 7.-Mean Conditional Probabilities Using Predicted Wealth from THE AUGMENTED REGRESSIONS

\begin{tabular}{lccccc}
\hline \hline & \multicolumn{2}{c}{ Model 1 } & & \multicolumn{2}{c}{ Model 2 } \\
\cline { 2 - 3 } \cline { 6 - 7 } \cline { 6 - 7 } & $\begin{array}{c}\text { Bottom } \\
20 \%\end{array}$ & $\begin{array}{c}\text { Bottom } \\
40 \%\end{array}$ & & $\begin{array}{c}\text { Bottom } \\
20 \%\end{array}$ & $\begin{array}{c}\text { Bottom } \\
40 \%\end{array}$ \\
\hline Underweight women & 0.307 & 0.538 & & 0.351 & 0.580 \\
Stunted children & 0.281 & 0.508 & & 0.317 & 0.561 \\
Wasted children & 0.298 & 0.516 & & 0.351 & 0.559 \\
\hline
\end{tabular}

The table gives proportions of the underweight who fall into the poorest $20 \%$ and $40 \%$ of the distribution of predicted values from regressions of log BMI on wealth and additional household and individual covariates. Means are population weighted.

women are found in the poorest $20 \%$ based on the predicted values from model 1 (table 7 ), as compared to $25 \%$ using only the household wealth index (table 3). Focusing instead on the poorest $40 \%$, the proportion rises to $54 \%$ using model 1 , as compared to $48 \%$ using wealth alone. Adding the individual variables (model 2), we now find that $35 \%$ of underweight women on average are found in the poorest $20 \%$ in terms of the predicted values, rising to $58 \%$ for the poorest $40 \%$. Similar improvements are evident for both stunting and wasting in children.

Among all the changes we have considered, these augmented regressions do the most to raise the conditional probabilities. This is possibly not surprising given the large amounts of extra data used and the fact that the predicted values are calibrated to explaining individual attainments. That appears to be rare in practice; for example, popular PMT methods are calibrated to explain household consumption rather than individual nutritional status (Brown et al., 2018). Nor is it surprising that the probabilities generally reach their highest values when one includes individualized data; household data alone cannot be expected to do as well. However, based on table 7, it cannot reasonably be said that even these predicted values based on augmented regressions calibrated to nutritional status do a good job at identifying undernourished individuals within households.

\section{Conclusion}

Focusing on a key but neglected informational constraint on effective policy interventions in practice, we have asked whether household poverty might provide a reliable guide for policy efforts trying to reach nutritionally deprived individuals, as indicated by anthropometric measures. We do not claim that information is the only constraint. Even if undernourished women and children are mainly found in wealth- or consumption-poor households, other factors, such as the local health environment and intrahousehold resource allocation, can play an important role in determining policy effectiveness.

Individual welfare clearly depends on more than nutritional status, and we cannot rule out the possibility that householdlevel data are more revealing for other nonnutrition dimen-

undernourishment as undernourished, thereby equaling the rate of actual and predicted undernourishment. sions. That said, undernutrition is an undeniably important dimension of individual well-being, and it has long played a central role in the measurement of poverty using household data. This dimension of welfare is also emphasized by policymakers concerned with reducing both current and longer-term poverty. The mounting evidence on the longer-term costs of stunting in young children adds force to that emphasis.

A great deal has been learned about the socioeconomic differentials in individual health and nutrition from microdata, typically using cross-tabulations or regressions. This knowledge is valuable. However, there is a risk that the differentials in mean attainments often found between rich and poor households lead policymakers to be overly optimistic about the scope for reaching vulnerable individuals using household-level data. Just how adequate such data are for the policy purpose of reaching vulnerable women and children has been unclear.

To help improve our knowledge about this informational constraint on policy, this paper has provided a comprehensive study for thirty countries in sub-Saharan Africa. We find a reasonably robust household-wealth effect on individual undernutrition indicators for women and children. Nonetheless, on aggregating across the thirty countries we studied, about three-quarters of underweight women and undernourished children are not found in the poorest $20 \%$ of households when judged by the household wealth index in the Demographic and Health Surveys. A similar pattern is found in the available household surveys that allow a comparison of individual nutritional measures with an estimate of the household's consumption per person, which is clearly the most widely used welfare metric in measuring poverty in developing countries. Adding other household variables-interpreted as either a reweighting of the DHS wealth index or as supplementary variables-improves the performance of household data, but we still find that a large share of undernourished individuals are not among those predicted to be undernourished based on household variables.

We have shown that more individualized (intrahousehold) data for fine targeting can help, though there are likely to be limits to how far this can go in practice. Indeed, an attraction to policymakers of targeting poor households is that doing so is expected to reach poor individuals without requiring intrahousehold data. In fact, we find that only $40 \%$ of children in the poorest households are stunted and less than $10 \%$ are wasted; for women, only $15 \%$ are underweight. This suggests that nutrition-based programs targeted to such poor households will be more successful in reaching individuals who are adequately nourished than those who are undernourished.

Instead, policymakers need to consider broader coverage, not focusing solely on households identified as poor. This is especially true in countries with a high overall incidence of undernutrition. Rather than folding nutrition schemes into household-targeted antipoverty programs in such countries, emphasis should instead be given to nutritional interventions with broader coverage that aim to reach 
vulnerable individuals, such as comprehensive school feeding (with explicit nutrition supplementation and deworming), maternal health care, and sanitation services.

In addition to documenting the limitations of relying on household poverty data to reach nutritionally deprived individuals, we have thrown some light on why those limitations are so severe, though we acknowledge that our findings are not conclusive in this respect. Simulations indicate that intrahousehold inequality in nutritional outcomes is a contributing factor to lowering the conditional probabilities, but other factors are clearly also playing an important role. We find evidence consistent with the view that covariate risks found in the local health environment help explain why undernutrition in children is spread so widely across the distribution of household wealth in sub-Saharan Africa.

\section{REFERENCES}

Agarwal, Neha, Anaka Aiyer, Arpita Bhattacharjee, Joseph Cummins, Christian Gunadi, Deepak Singhania, Matthew Taylor, and Evan Wigton-Jones, "Month of Birth and Child Height in 40 Countries," mimeograph Department of Economics, University of California, Riverside (2017).

Alderman, Harold, Michael Lokshin, and Sergiy Radyakin, "Tall Claims: Mortality Selection and the Height of Children in India," Economics and Human Biology 9 (2011), 393-406.

Anderson, Siwan, and Debraj Ray, "Missing Unmarried Women," Journal of the European Economic Association, forthcoming.

Bhutta, Zulfiqar, Jai Das, Arjumand Rizvi, Michelle Gaffey, Neff Walker, Susan Horton, Patrick Webb, Anna Lartey, and Robert Black, "Evidence-Based Interventions for Improvement of Maternal and Child Nutrition: What Can Be Done and at What Cost?" Lancet 382 (2013), 452-477.

Boerma, Ties, Elisabeth Sommerfelt, and George Bicego, "Child Anthropometry in Cross-Sectional Surveys in Developing Countries: An Assessment of the Survivor Bias," American Journal of Epidemiology 135 (1992), 438-449.

Bozzoli, Carlos, Angus Deaton, and Climent Quintanta-Domeque, "Adult Height and Childhood Disease," Demography 46 (2007), 647-669.

Bredenkamp, Caryn, Leander R. Buisman, and Ellen Van de Poel, "Persistent Inequalities in Child Undernutrition: Evidence from 80 Countries, from 1990 to Today," International Journal of Epidemiology 43 (2014), 1328-1335.

Brown, Caitlin, Martin Ravallion, and Dominique van de Walle, "A Poor Means Test? Econometric Targeting in Africa," Journal of Development Economics 134 (2018), 109-124.

Coady, David, Margaret Grosh, and John Hoddinott, Targeting Transfers in Developing Countries: Review of Lessons and Experience (Washington, DC: 2004).
Del Ninno, Carlo, and Bradford Mills, eds., Safety Nets in Africa: Effective Mechanisms to Reach the Poor and Most Vulnerable (Washington, DC: World Bank, 2015).

Djuikom, Marie Albertine, and Dominique van de Walle, "Marital Shocks and Women's Welfare in Africa," World Bank, Policy Research working paper 8306 (2018).

Fiszbein, Ariel, and Norbert Schady, Conditional Cash Transfers for Attacking Present and Future Poverty (Washington, DC: World Bank, 2010).

Hoddinott, John, John Maluccio, Jere Behrman, Rafael Flores, and Reynaldo Martorell, "Effect of a Nutrition Intervention during Early Childhood on Economic Productivity in Guatemalan Adults," Lancet 371 (2008), 411-416.

Larsen, Anna Folke, Derek Headey, and William A. Masters, "Misreporting Month of Birth: Implications for Nutrition Research," IFPRI discussion paper 01617 (2017).

Ravallion, Martin, "Income Effects on Undernutrition," Economic Development and Cultural Change 38 (1990), 490-515.

The Economics of Poverty. History, Measurement, and Policy (New York: Oxford University Press, 2016).

Richard, Stephanie, Robert Black, Robert Gilman, Richard Guerrant, Gagandeep Kang, Claudio Lanata, Kåre Mølbak, Zeba Rasmussen, Bradley Sack, Palle Valentiner-Branth, William Checkley, and Childhood Infection and Malnutrition Network, "Wasting Is Associated with Stunting in Early Childhood," Journal of Nutrition: Nutritional Epidemiology 142 (2012), 1291-1296.

Ruel, Marie, Harold Alderman, and Maternal and Child Nutrition Study Group, "Nutrition-Sensitive Interventions and Programmes: How Can They Help to Accelerate Progress in Improving Maternal and Child Nutrition?" Lancet 382 (2013), 536-551.

Steckel, Richard, "Stature and the Standard of Living," Journal of Economic Literature 33 (1995), 1903-1940.

Svedberg, Peter, "Undernutrition in Sub-Saharan Africa: Is There a Gender Bias?" Journal of Development Studies 26 (1990), 469-486.

Ulijaszek, Stanley, and Deborah Kerr, "Anthropometric Measurement Error and the Assessment of Nutritional Status," British Journal of Nutrition 82 (1999), 165-177.

UNICEF, Levels and Trends in Child Mortality (New York: UNICEF and collaborating agencies, 2011).

Victora, Cesar, "The Association between Wasting and Stunting: An International Perspective," Journal of Nutrition 122 (1992), 11051110.

Walker, Susan, Theodore Wachs, Julie Gardner, Betsy Lozoff, Gail Wasserman, Ernesto Pollitt, and Julie Carter, "Child Development: Risk Factors for Adverse Outcomes in Developing Countries," Lancet 369 (2007), 145-157.

Wamani, Henry, Anne Nordrehaug Åstrøm, Stefan Peterson, James K. Tumwine, and Thorkild Tylleskär, "Boys Are More Stunted Than Girls in Sub-Saharan Africa: A Meta-Analysis of 16 Demographic and Health Surveys," BMC Pediatrics 7 (2007), 17-27.

World Health Organization, From Promise to Impact: Ending Malnutrition by 2030 (Geneva: World Health Organization, 2016). 